\section{Autonomy and the Orthodoxy of Human Superiority}

\author{
Bart Gruzalski \\ Pacific Center for Sustainable Living
}

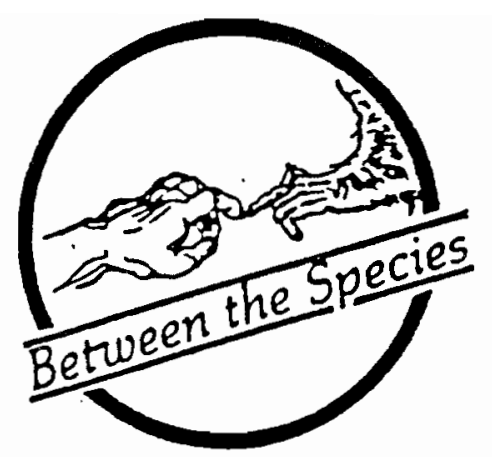

Editors' Note: An earlier version of this paper by Bart Gruzalski, the response by Professor Frey, and the reply by Gruzalski were presented at the Pacific Division meetings of the Society for the Study of Ethics and Animals, held in San Francisco, March, 1993.

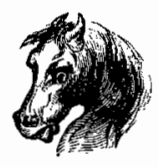

The capacity to propose an end to oneself is the characteristic of humanity (as distinguished from animality).

Immanuel Kant ${ }^{1}$

What is this joy? That no animal falters, but knows what it must do? Denise Levertov ${ }^{2}$

Philosophers, who rarely agree on anything, have reached a surprisingly strong consensus that human life, because of autonomy, is more valuable than nonhuman life. According to the consensus view, our lives are more valuable than the lives of nonhuman animals because of a richness in our lives that derives from autonomy and autonomy-based abilities, with an emphasis on an ability to mold our life to some conception we have of how life should be. The great 19 th century philosopher Immanuel Kant expressed an early version of the consensus account when he wrote: "The capacity to propose an end to oneself is the characteristic of humanity (as distinguished from animality)."3 Below I will discuss two contemporary philosophers who express and defend versions of this consensus view.

Because nonhuman animals exhibit some degree of what may be taken to be autonomy, we must clarify the degree of autonomy presupposed by the consensus account. To do this, it will be helpful to contrast how we are when we cook, or make chairs, or give lectures, with how we are when we become cooks, or become carpenters, or become teachers. When we do any of the latter, we likely will have standards, values and ambitions, and might mold our lives in accord with them. This will automatically involve us in a more sophisticated kind of autonomy than just the ability to make choices. Goats and chickens make choices, but we do not believe that they use standards and values to mold their choices, their lives, or to live out some ambition. Someone who just cooks may not do that either, but a person who thinks of himself as a cook, who wants to become a better cook, or a respected cook-that clearly brings in ambitions we do not believe we share with goats and chickens. It is in this fuller sense of autonomy, the sense in which we have standards and can mold our lives in accord with them, that our lives allegedly are richer and, hence, of more value.

For our lives to be more valuable than the lives of nonhuman animals because we are autonomous, each of the following claims would need to be true:

1. autonomy does add positive value to a life, and

2. a life with this added value is typically more valuable than any life lacking autonomy.

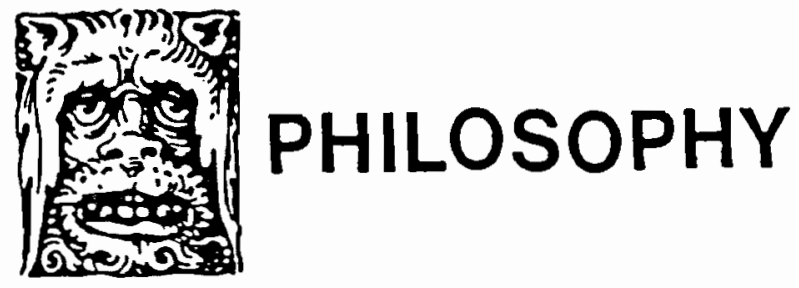


Claim (2) is important in order to insure that the value added by autonomy is not balanced by some ability a non-autonomous being might have, e.g., the ability to fly like a bird. We will explore these claims in turn.

\section{Does autonomy add positive value to a life?}

We begin with (1). Are our lives better than they otherwise would be because we are able to live out our conceptions of the good life and judge ourselves and others? A negative answer leaps to mind: because of the way people try to live out conceptions of the good life, we have genocide, rape, murder, depression, nuclear bombs, eradicated rain forests, extinctions, a depleted ozone layer, the greenhouse effect, and other conditions that make our own species vulnerable to extinction. Scientists have become so concerned about the environmental ramifications of humans trying to live out conceptions of the good life that the Union of Concerned Scientists issued a "Warning to Humanity" signed by a majority of the living Nobel science laureates in December, 1992. That document warned: "If not checked, many of our current practices put at serious risk the future that we wish for human society and the plant and animal kingdoms, and may so alter the living world that it will be unable to sustain life in the manner we know." 4

This negative answer about whether our lives are better than they otherwise would be because of autonomy is plausible. But taking an external perspective does not address whether autonomy adds a dimension of value from an inner perspective, the perspective from which autonomy plausibly might add value to life and the perspective at stake in discussions within contemporary western philosophy. ${ }^{5}$ In what follows, I focus only on the value of a life to its possessor, on whether an individual life is valuable from the inner perspective of that life. Given an inner perspective, it does seem plausible that an ability to judge and mold a life, an ability that requires intellectualizing, judging, and effort, adds positive value.

We find challenges even to this view. Christ, for example, tells us to "judge not," suggesting that the life of planning, worrying and striving are not the way to be:

And why take ye thought for raiment? Consider the lilies of the field, how they grow; they toil not, neither do they spin; and yet I say unto you, That even Solomon in all his glory was not arrayed like one of these.... Take therefore no thought for the morrow: for the morrow shall take thought for the things of itself.(Matthew: 6:28-31)

Reflections like these may support doubts about whether our ability to be autonomous and so be complicated, unspontaneous, and "in our heads" makes our lives more valuable from an inner perspective than the lives of beings who are spontaneous and more in touch with things of the heart.

These doubts are not alien to us. In myth, song, and both philosophical and religious works, we are often taught to lose our self-consciousness, to be natural and spontaneous, to stop worrying, and, in short, to become more instinctive, intuitive, and animal-like. We often think we become better and wiser when we transcend the self-conscious rationality celebrated in the orthodox view as a constituent of what enriches our lives and so makes them more valuable than the lives of nonhuman animals. When Zen master Bankei said, "my miracle is that when I feel hungry I eat, and when I feel thirsty I drink," he was expressing precisely this at-one-ness from which we in the "modern" world often feel alienated because of our self-conscious and judgmental approach to life.

But philosophers have provided reasons in support of the consensus view, and we shall examine two of them.

a. Philosopher Susan Wolf claims that the life of an autonomous being is richer and, hence, more valuable than the life of a non-autonomous being because with autonomy comes this ability to be moral. A being who has the ability to be moral is assumed superior to a being who lacks the ability.

b. Philosopher Raymond Frey claims that the exercise of autonomy leads to more felt satisfaction than, apparently, what is available to beings lacking autonomy. We will examine each of these reasons in turn.

\section{(a) The superiority of a being who can be moral}

According to philosopher Susan Wolf, most philosophers think human beings are more valuable than chickens and goats for the following reasons:

What is especially valuable about persons is connected to the fact that persons live, or have 
the potential to live, richer lives than other beings. Persons are capable of aspiring to and achieving a diversity of ideals... are capable of... exhibiting and appreciating moral virtue, and of understanding and committing themselves to moral laws. ${ }^{6}$

Physician and philosopher Willard Gaylin also claims that human beings are superior to nonhuman beings because we human beings can develop "that awareness of the right and good which enables us to act rationally, justly and virtuously thus defining human beings as the only moral animal."7 But are they correct: are the lives of beings who are able to be moral more valuable than the lives of beings who lack this ability?

The argument that lives enabled by autonomy are more valuable than lives lacking autonomy because autonomous beings alone have the ability to act morally rests on two claims. First, the claim that humans are the only moral animal. Second, that being able to act morally, or to refrain from acting morally, shows we are superior to beings who lack this ability. For the purposes of discussion, let us assume what is controversial, namely, that nonhumans do not have the ability to act morally or to respond to moral realities. Does this, of itself, resolve our question about worth and superiority?

Once we posit that humans alone are able to respond to moral concerns, we may seem to have already conceded that we are "superior" to nonhumans. This is what Willard Gaylin assumes when he claims that our moral qualities make us human and "elevate" us "above the common animal host." ${ }^{8}$ That is, of course, one natural way to look at the matter. We "have" more, so we are "better. "But are we correct in believing that the ability to be moral, and so the ability to be immoral, makes us better than beings that lack this ability?

Consider the following passage about beings for whom moral laws have no practical implications because the choices made by such beings and the moral law are necessarily in unison:

The "ought" is here out of place, for the volition of itself is necessarily in unison with the law.

The passage is from Kant, the will which is not restricted by such obligations is referred to as a holy will, and the holy will cannot but act in unison with the law. Kant's notion of a holy will is important and relevant for our discussion, since it shows that a being can lack an ability and yet be "superior" to a being which has this additional capacity. According to Kant, God's will is a holy will: God cannot but act in accordance with the law, and yet God's will is superior to the imperfect human will which can and often does act contrary to the law. That God lacks the ability to be moral (or immoral) is sufficient to show that this ability does not make a life inherently more valuable than a life lacking this ability. Our assumption that nonhuman animals cannot make moral choices and that the "ought" is out of place for them does not, therefore, show that our lives are more valuable than theirs.

That nonhuman animals lack autonomy is not only consistent with the view that nonhuman animals do not need to be restricted by laws of morality, but is also consistent with the view that they act spontaneously and in this way may be superior to us. In her poem, "Come Into Animal Presence," Denise Levertov evokes this possibility. After noticing that "the llama intricately folding its hind legs to be seated not disdains but mildly disregards human approval" and remarking on her own "joy when the insouciant armadillo glances at us and doesn't quicken his trotting across the track into the palm brush," she raises a question that gives rise to a pertinent answer: "What is this joy? That no animal falters but knows what it must do?" She builds on this theme, ending her poem with reflections on holiness and joy:

\section{...The llama}

rests in dignity, the armadillo

has some intention to pursue in the palm-forest.

Those who were sacred have remained so,

holiness does not dissolve, it is a presence

of bronze, only the sight that saw it

faltered and turned from it.

An old joy returns in holy presence. ${ }^{10}$

The poet suggests that we are not as holy as spontaneous nonhuman animals and that our added capacity to assess what we should do not only fails to make us superior but, by causing us to "falter," opens up the possibility that they are superior to us.

We have explored whether our lives are more valuable than the lives of nonhuman animals because our autonomy confers upon us the ability to be moral. What we find is that the ability to be moral does not 
make our lives inherently more valuable than lives lacking this ability. Hence, even if we assume, what is controversial, that nonhumans lack the ability to be moral, it does not follow from this "lack" that their lives are less valuable than our own.

\section{(b) "Considerable satisfaction" and the more valuable life}

There is a second defense of the consensus account. According to this defense, the exercise of autonomy leads to more felt satisfactions. Philosopher R. G. Frey expresses this view as follows:

By exercising our autonomy or agency, we can mold and shape our lives to fit a conception of the good life of our own choosing, and living out this conception can itself supply us with a strong sense of achievement and of self-fulfillment, and, through these, with considerable satisfaction.... Nothing comparable exists among the non-autonomous. We have here, then, a further reason for thinking that the lives of normal humans are much richer than those of infants, defective humans, and animals. ${ }^{11}$

If we do experience more satisfaction than beings lacking our degree of autonomy, that might provide some plausibility to the thought that our lives had a higher quality than beings who do not experience these autonomy-related satisfactions. But do the autonomous experience more satisfaction than those who lack autonomy?

The exercise of autonomy, on Frey's account, involves pursuit: shaping and molding our lives to fit an idea we have of how we want our lives to become. According to Frey, implementing our idea of the good life causes us positive feelings. This is the source of the value unique to autonomous lives: the positive feelings coming from successful pursuits of the good life of our choosing.

When we investigate the details of the likelihood of increased satisfaction for the autonomous, Frey's claim becomes less plausible. Although Frey writes in terms of success ("living out this conception"), the best we can do is to try to implement our conception of the good life. That, of course, involves us not only in successes, but in failures. We must weigh each of these outcomes in our final assessment of the value of autonomy.
When we are not successful, we do not have more felt satisfaction-instead, we may experience feelings of failure, frustration, and disappointment, or even feelings of anger and despair, and, so, much less satisfaction. Failures in achieving our ideas of the good life of our choosing do not support Frey's evaluation of the autonomous life as better. So, let us assume at least initial success. Does initial success insure positive satisfaction for the autonomous?

When we are successful, typically we are in one of two situations. Either we have succeeded in a way that seems permanent-achieved better health, improved our job situation, purchased a home, entered into a promising relationship, made money, enhanced our reputation-or we have succeeded in enjoying something that we know to be momentary-a concert, a kiss, a meal.

Once we've obtained what is in the more permanent group, generally we will desire to keep or improve on these goods. Our wanting to keep what seems permanent involves us in new efforts and a new round of successes and failures. Impermanence has many faces: sickness and accidents undermine health; relationships change; jobs become undesirable; natural disasters destroy homes; expenses drain savings; and reputations are mercurial. Even if we are able to "hold on" until old age, in dying we must lose everything that we pursued and acquired. Trying to keep any of these goods eventually leads to the experience of loss.

When we turn to the enjoyment of what is clearly momentary, we will want to experience these goods again under the appropriate conditions. The tendency of desire for more and better makes it more difficult to recreate satisfactory momentary pleasures. Concerts, meals and kisses each suffer from heightened expectations, for satisfactorily repeating an experience, especially when we have higher expectations for that experience, becomes more difficult than earlier successes with lower expectations. Frustration at these difficulties is also part of the desire-oriented way of life.

These reflections constitute the first reason for doubting that the exercise of autonomy leads to more overall satisfaction: it is precisely the frustration of our preferences, plans and ambitions that causes much human suffering. Our most important desires-for example, that we and our loved ones do not die-will be frustrated, and the amount of felt dissatisfaction from thwarted preferences plausibly defeats whatever positive value satisfied preferences add to a life. 


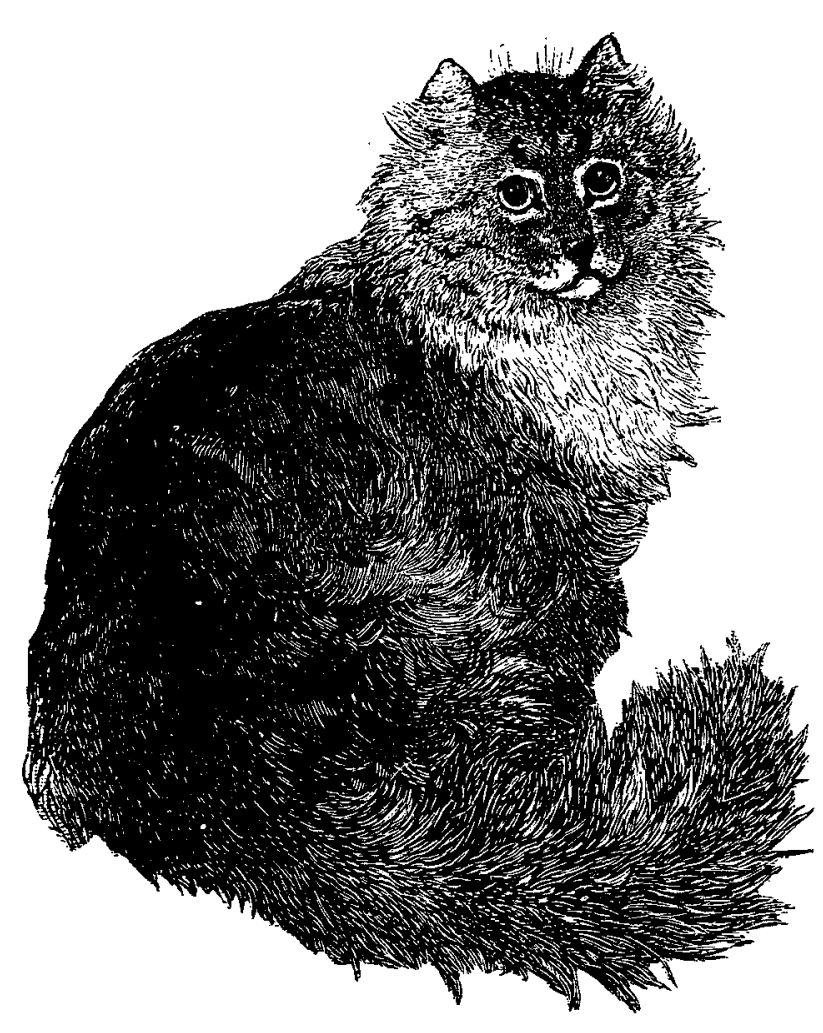

The second reason for doubting the overall satisfaction of the autonomous life is that the exercise of autonomy, on Frey's account, requires that we attempt to make changes and, so, pulls our attention from the present and puts it on what may happen in the future. By attending to what is not present, we are not as fully appreciative of whatever is unfolding. For example, if I am hiking up a hill and am thinking about the vista I am about to reach, I will be less attentive to the flora along the trail. ${ }^{12}$ In this way, we miss sunsets, the taste of our meals, the subtle colors of the trees along our roadways, and the songs of birds.

We can be lost to the present by focusing either on the future or on the past, as the following Zen story about two monks illustrates:

Tanzan and Ekido were once traveling together down a muddy road. A heavy rain was falling.

Coming around a bend, they met a lovely girl in a silk kimono and sash, unable to cross the intersection.
"Come on, girl," said Tanzan at once. Lifting her in his arms, he carried her over the mud.

Ekido did not speak again until that night when they reached a lodging temple. Then he no longer could restrain himself. "We monks don't go near females," he told Tanzan, "especially not young and lovely ones. It is dangerous. Why did you do that?"

"I left the girl there," said Tanzan. "Are you still carrying her? ${ }^{13}$

One imagines Ekido, as they walked along, judging Tanzan negatively. It is not implausible to think that Ekido did not notice the birds and plants along the road as fully as he otherwise would have were he not thinking about what was past (Tanzan's lifting the girl) and about the future (whether, what and when he would say something to Tanzan). All of this, it is plausible, put Ekido in a rather sour mood, his judgmentalness itself diminishing the felt satisfactions of the experience.

That judgmentalness undermines the quality of momentary experiences is the third reason for thinking that Frey's account of the value of autonomy is not plausible, since the functions of autonomy involve implicit judgments that things are not good enough the way they are. For example, we strive for achievement and more fulfillment because we have a conception of the good life that we believe we are not fully realizing. Since we can imagine how almost any experience, situation, relationship, or success can be better-nearer to perfection, more intense, more refined-judgmentalness can undermine the satisfactoriness of experiences, situations, relationships, and successes and, so, depreciate their quality.

Motivated by this tendency to judge as not fully adequate what otherwise might have proven to be completely satisfactory, we find ourselves turning to accumulation, competition, and what is sanctioned by those in society whom we respect, envy, or admire. As a result we typically come to discount precisely what we found full of wonder when we were children and what those who are dying often say is truly valuable. Recall Ivan Ilych, a successful and wealthy judge, on his deathbed:

And in imagination he began to recall the best moments of his pleasant life... the further he 
departed from childhood and the nearer he came to the present the more worthless and doubtful were the joys....then that deadly official life and those preoccupations about money.... It occurred to him that what had appeared perfectly impossible before, namely that he had not spent his life as he should have done, might after all be true....his professional duties... and social and official interests... false. ${ }^{14}$

Molding our lives to fit some idea we have of what is good can easily cause us to pursue what society or others claim is valuable and, so, discount precisely what was available and could have been perfectly satisfactory but for our judgmentalness.

This is hardly a message only from the dying. ${ }^{15}$ In the following, from an interview on environmental issues, Dave Foreman has been asked when he is the happiest. Foreman answers:

When I'm not thinking abstractly. When I am being fully an animal, when I' $m$ in the middle of a rapid on the river and having to respond to the river. I'm happiest when I experience the moment entirely for what it is. I'm happiest when I'm bird-watching, or when I'm walking down a trail in the wilderness and the internal dialogue finally ceases-I'm just there in the place. Our physical adaptation is for running or moving through wild country. That's when we're truly human and truly alive.... I recently had the joy of my life when I came in contact with a Jaguar on the Monkey River in Belize. Rationality ceased, abstraction ceased. We ignore the fact that we need wilderness around us to be mentally healthy. ${ }^{16}$

Foreman claims to be happiest when rationality and abstraction cease, when he is experiencing the present as it is. And also, we can surmise, when judgmentalness ceases. Think of how Foreman's experience of the jaguar changes if he's judging: Is this jaguar one of the biggest reported? Or: Will it make a good photograph? Or: Has this jaguar been documented in any scientific study? Any of those perspectives, easily part of a "good life of our choosing," would take away from the quality of the experience that Foreman describes. And what makes the diminutive difference is the addition of the faculty of judging.
The exercise of autonomy, as Frey describes it, involves the autonomous in attachments and pursuits that, when disappointed, will cause suffering. It requires that the autonomous not attend as fully as they can to the present moment and thereby diminishes the quality of momentary experiences. And it involves the autonomous in making judgments that diminish felt satisfactions. In short, it is not plausible to think that autonomy adds positive qualities to a life. The Buddha confirms this conclusion in the Second Noble Truth, where he states that it is our attachment to desire and aversion that causes our suffering. All of this undermines the plausibility of the claim that, when everything is taken into account, the exercise of autonomy adds satisfaction to a life.

\section{Would a value added by autonomy surpass any other added values?}

In examining these two defenses of the claim that autonomy makes our lives more valuable, we have seen that this orthodoxy is plausibly false. Nonetheless, it will be useful to proceed to the second question, modified to reflect our discussion so far. So modified, our question becomes: Supposing, apparently contrary to fact, that autonomy did add value to a life, are lives with the added dimension of value supplied by autonomy more valuable than lives without this value?

The added dimension of value in question comes from our having an ability to judge and to mold our lives. What reason, that is not question-begging, could possibly show that this ability, unique to normal adult human animals, makes our lives more valuable than the lives of other apparently satisfied animals, human or nonhuman, who did not have this ability? All of us are able human beings; we pursue what we think of as good-but does this make our lives more valuable than the life of a Canadian goose or a severely retarded person with Down's Syndrome? The Canadian goose has the ability to fly, can ride air currents, read weather patterns, and migrate many hundreds of miles annually. Down's Syndrome persons tend to be happier and more loving than those of us who are "normal." Our abilities differ from those of geese, and those of us in the bustle of urban or academic life are typically not as happy or loving as the person with Down's Syndrome. But we knew all of this at the start. To add that our abilities make us superior seems only to beg an evaluative question by assuming precisely what is in question. 
The most we seem justified to say, in addressing question (2), is that we lead lives that in many ways are similar to the lives of other animals, and in some ways are different.

\section{Conclusion}

In this paper I have chronicled the failure of two defenses for the orthodoxy that the autonomous life is more valuable than the non-autonomous life. We have also seen why it becomes plausible to think that the very traits we have been inclined to cite as the grounds of our human superiority may, contrary to orthodox opinion, diminish the quality and the fullness of the lives we lead. This possibility suggests that it may not be "we" who are superior, but our animal brothers and sisters who live out their own natures in a more spontaneous fashion. To many of us, this would seem like a perverse pronouncement, which seems part of what the poet Blake had in mind when he wrote:

As I was walking among the fires of hell, delighted with the enjoyments of Genius, which to Angels look like torment and insanity, I collected some of their Proverbs; thinking that as the sayings used in a nation mark its character, so the Proverbs of Hell shew the nature of Infernal Wisdom better than any description of buildings or garments.

When I came home: on the abyss of the five senses, where a flat sided steep frowns over the present world, I saw a mighty Devil folded in black clouds, hovering on the sides of the rock, with corroding fires he wrote the following sentence now perceived by the minds of men, \& read by them on earth:

\section{How do you know but ev'ry Bird that cuts the airy way, \\ Is an immense world of delight, clos'd by your senses five $?^{17}$}

And, surely, there is nothing in our argumentation or thinking that would even begin to show that birds are not happy and blissful: they sing in the morning, fly in play, care devotedly for their young, and finally sing again towards dusk. How many humans sing or play as well? Even Christ, in the Sermon on the
Mount, used birds as an example of how we should be, instead of how we are when we worry about sowing and reaping.

Ancestors of this paper were also presented at a Central Division American Philosophical Association meeting and a colloquium at Northeastern University.

I am grateful for comments on the earlier versions of this paper by, among others, Michael Bradie, David DeGrazia, R. G. Frey, Rama Rao Pappu, and Steve Sapontzis.

\section{Notes}

1 Immanuel Kant, The Metaphysical Principles of Virtue, translated by James Ellington (New York: Bobbs-Merrill, 1964): 391, p. 50. Kant first published this work in 1797.

${ }^{2}$ Denise Levertov, "Come Into Animal Presence," in Robert Bly's anthology, News of the Universe (San Francisco: Sierra Club Books, 1980), p. 150.

${ }^{3}$ Kant, op. cit.

4 "Warning To Humanity" (Cambridge, Massachusetts: Union of Concerned Scientists, 1992).

${ }^{5}$ Here I follow James Rachels, The End of Life (Oxford: Oxford University Press, 1986), p. 26.

${ }^{6}$ Susan Wolf, "Self-Interest and Interest in Selves," Ethics 96 (1986), pp. 708-709.

${ }^{7}$ Willard Gaylin, The Philosopher's Index (Bowling Green, Ohio: Philosophy Documentation Center, 1986) Vol. 20, p. 372. This quote is from a short abstract by Willard Gaylin of his "Feeling," published in Powers That Make Us Human (Urbana: University of Illinois, 1985), ed. Kenneth Vaux. In this abstract, Gaylin claims: "Among those aspects that distinguish Homo Sapiens from the lower animals... is the range of human feelings.... Feelings - particularly the so-called "negative" feelings like guilt and shamepositively and creatively harnessed, sharpen the moral sense, developing that awareness of the right and good which enables us to act rationally, justly and virtuously thus defining human beings as the only moral animal." But in the article itself there are only a handful of references to nonhuman animals, and at none of them does Gaylin present the argument he provides in his abstract. Gaylin twice states that guilt is an emotion that distinguishes us from other species (pp. 62 and 67), and on one page argues that nonhuman animals experience guilty fear but not guilt (p. 67). 
On the last page of the article Gaylin uses language to indicate his view of the superiority of the human to the nonhuman: "If the love and caring are supplied only minimally, he [a human being] may survive as a biological entity without the qualities of humanness that elevate him above the common animal host. If at any key point an individual is withdrawn from contact with his kind, he may recreate social relationships in his imagination that sustain him for a time, but he suffers the risk of being reduced to an animal indistinguishable from lower forms"(p. 72, italics mine). But there is no argument at all in the paper to the effect that we alone are moral animals, and no argument for the superiority of human to nonhuman animals. The focus of the article is chiefly a discussion of the emotion of guilt. What distinguishes the human from the nonhuman, however, is instead the focus of the abstract, as is Gaylin's claim that human beings are defined as the only moral animal. That claim is relevant to the topic of this paper.

${ }^{8}$ Gaylin, "Feeling," op. cit., p. 72.

${ }^{9}$ Immanuel Kant, Foundations of the Metaphysics of Morals(New York: Bobbs-Merrill Company, 1959): 414, p. 31.

${ }^{10}$ Levertov, op. cit.

${ }^{11}$ R. G. Frey, "The Significance of Agency and Marginal Cases," Philosophica 39 (1987), p. 40.

${ }^{12}$ I may also be less satisfied when I reach the vista-if my expectations are too high-precisely because of my forward-looking approach. But that is the third problem with Frey's argument, that judgmentalness (concomitant with high expectations) diminishes the felt satisfactions even of experiences that would have been perfectly satisfactory otherwise.

${ }^{13}$ Zen Flesh, Zen Bones (Garden City, New York: Anchor Books, 1957), ed. by Paul Reps, p. 18.

${ }^{14}$ Leo Tolstoy, The Death of Ivan Ilych (New York: New American Library, 1960), pp. 147-148 and 152.

${ }^{15}$ Although Ivan Ilych is a fictional character created by Tolstoy, Tolstoy's characterization of one progression of attitudes and insights through the dying experience has been confirmed as both realistic and not uncommon by those who work with the dying, according to conversations with Marion Wilson Gruzalski, who has founded two hospices, developed a third, and consulted for many more.

${ }^{16}$ Derrick Jensen, Listening to the Land: Conversations about Nature, Culture, and Eros (San Francisco: Sierra Club Books, 1995), p. 6. Dave Forman is the founder of the activist group Earth First! and, more recently, the Wilderness Project.

${ }^{17}$ From "The Marriage of Heaven and Hell," in Bly, op. cit., p. 41 .

\section{Response:} Autonomy, Animals, and
Conceptions of The Good

\author{
R. G. Frey \\ Bowling Green State University
}

In a number of recent articles on animal issues, ${ }^{1} \mathrm{I}$ have set out one view of the comparative value of human and animal life. It is a view consonant both with my earlier writings on animals ${ }^{2}$ and with the emphasis upon quality of life accounts of the value of life that are so much a part of contemporary writing in medical ethics and in applied ethics generally. Numerous details of this quality of life view remain to be filled in, of course, but its general outline, I think, is clear enough. Even in general outline, however, some philosophers and others have found the view wanting, if not in its entirety, then certainly in some of its more prominent features. One feature that has proved especially controversial is that the value of some human lives can turn out to be of a quality so low as to be exceeded in value by the lives of some perfectly healthy animals, which in turn can have implications for, say, which creatures are to be used in medical experimentation. Another such feature, it would appear, has been my remarks on the role of autonomy in the value of human, as opposed to, animal lives. ${ }^{3}$ Bart Gruzalski's paper "Autonomy and The Myth of Human Superiority" is very much in this latter vein. I should like here briefly to respond to some of Gruzalski's comments, before trying to bring more sharply into focus certain features of the comparative view of the value of human and animal life that I hold. (In what follows, I leave aside Gruzalski's remarks on other philosophers.)

In a way, it is odd that Gruzalski puts me in the camp of those who espouse human "superiority." Most

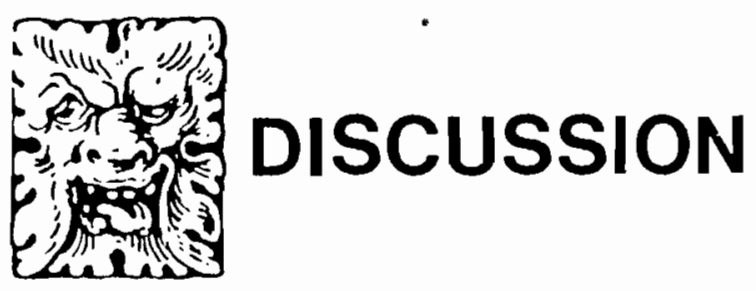

